\title{
Next Generation Launch Technology Program Lessons Learned
}

\author{
1st Space Exploration Conference: Continuing the Voyage of Discovery
}

\author{
AIAA-2005-2562 \\ Stephen Cook and Richard Tyson \\ NASA Marshall Space Flight Center
}

\section{Introduction}

In November 2002, NASA revised its Integrated Space Transportation Plan (ISTP) to evolve the Space Launch Initiative (SLI) to serve as a theme for two emerging programs. The first of these, the Orbital Space Plane (OSP), was intended to provide crewescape and crew-transfer functions for the ISS. The second, the NGLT Program, developed technologies needed for safe, routine space access for scientific exploration, commerce, and national defense.

The NGLT Program was comprised of 12 projects, ranging from fundamental high-temperature materials research to full-scale engine system developments (turbine and rocket) to scramjet flight test. The Program included technology advancement activities with a broad range of objectives, ultimate applications/timeframes, and technology maturity levels. An over-arching Systems Engineering and Analysis (SE\&A) approach was employed to focus technology advancements according to a common set of requirements. Investments were categorized into three "segments" of technology maturation: propulsion technologies, launch systems technologies, and SE\&A.

At the time of cancellation, the Program was pursuing the following major technology thrusts:

- Development of a reusable liquidoxygen/liquid-kerosene rocket booster engine.

- Development of hypersonic, air-breathing propulsion and airframe systems.

- Development of cross-cutting vehicle system technologies, intended to support a broad variety of launch and flight vehicle architectures.
- Systems analysis activities to guide program investment and to ensure an appropriate fit with both NASA and Department of Defense (DoD) needs.

The NGLT Program was intended to bring an array of technologies to a state of readiness appropriate to facilitate decisions near the end of the decade on whether or not to initiate a program for development of NASA's next generation of launch vehicle(s). The resulting new program would then be built, in large part, on the selected technologies from NGLT. In short, NGLT was NASA's investment in new space launch technologies for use primarily beyond the OSP.

The team charged with collecting and processing NGLT lessons learned began with a call to Program personnel. Subgroups of the team reduced an initial set of 315 inputs by assessment and combination to 100; a second and third cycle of assessment reduced those to a core set of 68 .

\section{Key Findings}

Of the total number of lessons learned, the following were considered to be the "key findings" from each theme. (These are cross-referenced to supporting lessons learned (unique identifier in parentheses) in Section 3.0.)

\section{A. Requirements}

- Systems analysis should be used to guide and assess technology development, beginning early in the program. Systems analysis should develop quantifiable priorities and requirements against which technology projects execute $(\mathrm{R} 1, \mathrm{R} 2)$. 
- Programs should establish reference mission and vehicles/requirements and then implement standard, well-documented flow-down practices to all technology activities, properly educating all personnel regarding those practices (R2, R3).

- Programs should carefully assess the impacts and relevancy of legacy projects toward program goals and objectives before committing resources (R4).

\section{B. Plan}

- Programs should define roles and responsibilities early and all the way down to the supplier level, and communicate and enforce established protocols, responsibilities, and team core values early and often so that expected standards of operation are established for the life of the program (P1).

- The formulation process should not be shortchanged-many critical issues will surface that will later drive cost and schedule (P2, P3, P4, P5).

- Programs should perform a thorough assessment of the manufacturing vendor capability required to produce space-qualified hardware for each development spiral (P6).

\section{Schedule}

- Adequate planning should be performed early and realistic schedules developed with both sufficient and visible margins. This should be done initially from as low a level as possible and integrated in coordination with functional leads and analysts (S1, S3, S4).

- An integrated master schedule should be developed early in the formulation phase, which can evolve to accommodate the maturity of the program (S2).

\section{Budget}

- Credible, independent cost estimates are required early in the project life-cycle (B1, T8).

- Initial budget estimates must include budget reserves and schedule margins for each major period of performance, with those reserves and margins assigned in proportion to the risk in each period. (B2).

- Program management should establish a centralized resource-integration function early; the resulting team should have the capability for program-wide budget planning, analysis, tracking, reporting, and change control (B3).

- Budget plans should take into account "real world" budget issues, such as delays and disbursements, continuing resolutions, and current limitations in the Integrated Financial Management (IFM) System (B4, B5).

\section{E. Agreements}

- Inter-Agency coordination of technology development should be pursued at the performing level (versus high-level, broadbased agreements), capitalizing on hardware developed and unique capabilities of the partner agencies (A1, A2).

- Partnering agreements should be comprehensive. These should include resources (including reserves and procedures for addressing cost growth) and Safety and Mission Assurance (S\&MA), as well as a clear definition of the roles and responsibilities of each team member (A3, A4, A5).

- International relations require constant attention. The NASA international agreements process should be streamlined. Programs should leverage existing international agreements to the greatest extent possible (A6, A7).

- When Centers perform work for contractors (e.g., through Government Task Agreements), the contractor must be given full responsibility and accountability for managing resources (A8).

- Programs should ensure that contracts allow for effective utilization of both government and industry resources: ask only for what the government can effectively use-no more(A9, A10)-and enable flexibility in the execution of future work (A11, A12, A13, A14).

\section{F. Execution}

- NASA engineering staffs should be utilized to provide technical insight/independent analysis in high-risk, mission-critical areas. NASA should plan and budget for the appropriate level of insight early in the program. Government insight teams and their industry counterparts should communicate on a regular 
basis and continuously look for ways to improve implementation methods (E1, E2, OD7).

- Greater prime contractor involvement in technology development programs helps to ensure that the products developed have more immediate utility and require less rework (E3, E4).

\section{G. Technology Integration}

- Rigorous systems engineering and systems analysis processes should be utilized for identifying technicai risk to accompiish requirements, technical performance metrics (TPMs), and figures of merit (FOMs) in the formulation stage. These should be used continuously to check progress against goals and objectives (T1, T3, T5).

- Programs should define, plan, and document the processes, procedures, and products for the SE\&A function as early as possible in formulation (T4).

- Programs should plan for and require adequate configuration control of analytical tools, models, and data sets and lock down the tool suite during analysis cycles (T6, T7).

\section{H. Organizational Design and Development}

- Dual project reporting paths cause confusion and introduce duplication of efforts. Clear lines of responsibility and authority are necessary for project success (OD1, OD2, OD4).

- Execution of broadly scoped, long-range programs requires an environment of demonstrated trust coupled with appropriate delegation and empowerment to lower-level management (OD3).

- Attention to the organization's discipline, structure, and development is vital to the success of the mission. Opportunities to improve these at all levels should be encouraged (OD4, OD5, OD6, OD7).

\section{Program Integration \& Communication}

- Integration is a key building block to an effective organization and should be performed on an on-going basis, especially at the middle-management level. A lack of integration, cited in the Columbia Accident Investigation Board (CAIB) Report as one of the causes of failure, is an issue in NASA's culture. This lack of integration results in turf battles, "stove-pipes," and chains of command issuing duplicate and confusing directives. These, in turn, adversely impact budget, schedule, and risk (PC1, PC3, PC5, PC6, PC7, PC8).

- Management should acknowledge employee concerns and have open, frank, and mutually respectful discussions. Such communication would allow for sharing "bad news" early and could shift the NASA culture to one of openness-with two-way, value-added, topdriven communication ( $\mathrm{PC} 2)$.

- Reporting and readiness reviews should be streamlined. Projects should use standardized practices where practical (PC4, E5).

\section{J. Safety and Risk}

- $\quad$ Risks should be identified and tracked early and mitigation options incorporated into the acquisition strategy and systems analysis process (SR1, SR4, SR5).

- A consistent, continuous risk management system should be utilized across the program and clear pass/fail criteria should be developed for risk reduction activities (SR2, SR3).

\section{Lessons Learned}

\section{A. Requirements}

This section addresses requirements for products as derived from organizational vision and mission statements and/or from specific charters or directives issued by higher authorities. They may be refined through architecture studies, feasibility studies, and other concept exploration.

\section{Establish an Early Link Between Systems Engineering \& Analysis and Technology Projects (R1)}

\section{Driving Events}

Several technology development activities from $2^{\text {nd }}$ Gen RLV and ASTP were combined to form the NGLT Vehicle Systems Research and Technology (VSR\&T) Project. Initially, there was no strong link between the VSR\&T Project and the SE\&A projects. This link was needed to ensure that the proper architectures and, hence, technologies were being addressed. 
Without the proper linkage to SE\&A, the VSR\&T Project may not have been addressing the critical technology requirements for the NGLT architectures under consideration. Later, the System Analysis Project (SAP) attempted to remedy the situation by interacting with the various NASA Centers conducting technology development. An Architectural Design and Technology Initialization Workshop was aiso held to bring together the various systems analysts and technology developers for NGLT, albeit after the fact.

\section{Lessons Learned}

Systems engineering and analysis should be linked to the technology development projects early in the program. Systems analysis should be used to develop quantifiable priorities and requirements against which technology projects should execute. The systems analysis activity should actively engage technology developers throughout the life cycle in developing requirements (working with hardware developerse.g., utilizing the "Value Stream" process), ensuring models are valid, assessing the progress of the project, and ensuring the continued relevance of the investment against other, competing priorities.

\section{Develop a Set of Reference Mission Requirements Early (R2)}

\section{Driving Events}

Due to the nature in which NGLT was formed, the SAP was forced to make certain assumptions regarding Program requirements in order to perform initial technology cost/benefit analyses. Once the first annual cycle started, requirements began to flow down from the Program, resulting in disconnects. This necessitated restarting the full cycle.

\section{Lessons Learned}

Programs should spend the time prior to each systems analysis cycle to develop and validate a reference set of mission requirements with customer, stakeholder, and analyst approval.

\section{Need for Early Reference Vehicle Conceptual Designs (R3)}

\section{Driving Events}

In the 2nd Gen RLV Program, the prime contractors developing the vehicle architectures held their proprietary design information very close. Subsystem-level technology developers, e.g., those focused on propulsion and thermal protection systems (TPSs), were forced to derive a broad set of performance requirements due to the lack of a focused vehicle architecture. It was difficult for the subsystem technology developers to determine an appropriate set of environments and performance/life cycle requirements. Although NASA attempted to generate top-level requirements documents, a reference mission, and vehicle architecture, the information flow was slow and, in many cases, nonexistent. In this case, the sub-element manager was forced to piece together design information from various prime contractors to arrive at a preliminary set of requirements encompassing all known vehicle architectures and environments.

\section{Lessons Learned}

A reference vehicle architecture, or clear performance specifications, should be in place prior to the initiation of technology development. A clearly defined process is required for both generating and flowing down system requirements (e.g., associated flight environments) to the subsystem level.

\section{Plan Early for Incorporating Legacy Technology Programs (R4)}

\section{Driving Events}

All NGLT activities were legacy projects from either the 2nd Gen RLV Program or the ASTP. While the legacy content represented strong candidates for any RLV application, it was not derived by applying consistent systems engineering practices (due to different parent programs). As a result, it was not possible to initiate a classical systems engineering process that would have driven out the needed technologies. This greatly complicated the NGLT systems engineering task.

\section{Lessons Learned}

The systems engineering team should be provided sufficient time to assess the cost/benefit of legacy projects and impacts of the new requirements on these projects.

\section{B. Plan}

This section is an articulation of the methods and systems to be employed for satisfying the requirements as well as their relationships. A plan typically combines considerations for technology, resources (e.g. budget, workforce, etc.), and schedule. As used herein, this includes the plan-both as a concept and document-as well as the actions required to develop the plan. Sections 3.3 and 3.4 will address issues specific to budget and schedule. 


\section{Clearly Define Roles, Responsibilities, and a Common Set of Values (P1)}

\section{Driving Events}

The Rocket Based Combined Cycle (RBCC) Project consisted of a consortium of prime contractors. Responsibilities were distributed throughout the consortium, but suppliers would only discuss issues with key decision makers, leaving the expediters and coordinators out of the information loop. In a multicontractor consortium, the team eventually developed a set of core values: trust, teamwork, and critical knowledge: unfortunately, this came late in the program. A system that encourages team behaviors and discourages divisive behaviors should have been developed and matured earlier.

\section{Lessons Learned}

Programs should define roles and responsibilities early all the way down to the supplier level with a clear focal point for communication. The government should play a key role in enabling the full team to communicate and enforce established protocols, responsibilities, and the team's core values early and often. This will provide expected standards of operation that are both established and fully understood for the life of the program.

\section{Plan for and Adequately Stafi the Project Team (P2)}

\section{Driving Events}

The X-43C Project was executed by the ASTP without performing a Non-advocate Review. This was based, in part, on similarity to the $\mathrm{X}-43 \mathrm{~A}$ (Hyper-X) Project. The scope of effort was also not fully understood or supported by the executing Center management. The first person assigned to the project was the Chief Engineer (CE), who also performed the Project Manager (PM) and Business Manager (BM) functions for nearly a year with minimal help from X-43A staff, who were working return-to-flight activities. The $\mathrm{CE}$ was eventually promoted to PM and a new CE and a BM were assigned. Project staffing continued to lag needs, thereby forcing existing project staff to work long hours under stressful conditions. A lack of adequate workforce in the early days of the project delayed development of plans and complicated the project's formulation. The X-43C's similarity to X-43A did not reduce workload during formulation as assumed.

\section{Lessons Learned}

Each project should be treated as a new effort with adequate staff from the outset. A PM, CE, and BM should be assigned when a project is initiated. Technical leads for critical areas, a Deputy Project Manager, a Mission Assurance Manager, and Risk Manager should also be assigned as soon as possible.

\section{Allow Time for Adequate Project Formulation, Even When Task Appears Low Risk (P3)}

\section{Driving Events}

Government cost estimates generated by the Booster and Launch Services (B\&LS) Project were in the $\$ 48 \mathrm{M}$ to $\$ 52 \mathrm{M}$ range. Initial Rough Order of Magnitude (ROM) estimates from the contractor were $80 \%$ higher than the government estimates. The final proposal for this effort was approximately $58 \%$ higher than government estimates, despite the fact that government estimates were derived from X-43A actual costs and were considered to be quite accurate. Differences between the previous X-43A effort and the $X-43 C$ effort were either unknown or underappreciated. Examples included contractor claims of hardware commonality and reusability, changes in governing range requirements, impacts due to both schedule and funding profile requirements, as well as increased technical and programmatic data requirements.

\section{Lessons Learned}

Do not underestimate the need for thorough project formulation and cost estimation, even when the project appears to be a straightforward follow-on effort.

\section{Thorough Preparation is Needed for Successful Acquisition Strategy Meetings (P4)}

\section{Driving Events}

The X-43C Project initially planned to award a solesource contract for the Demonstrator Vehicle (DV) based on similarity to the Hyper-X Program (X-43A). An unexpected level response to a sources-sought announcement revealed that a competitive procurement was feasible. Due to the size of the procurement, an Acquisition Strategy Meeting (ASM) was required. 
A successful ASM briefing was developed by the PM and Contracting Officer. Briefing charts were developed in a multi-step approach. Two "realistic" rehearsals were held by the head of the langley Research Center (LaRC) Procurement with numerous questions for the presenters. After the charts were reworked and preparations were made for potential questions, a final briefing was completed. This level of preparation enabled the presenters to provide required information and perform well at the actual ASM, answering all questions and providing a wellrehearsed and smooth briefing. The ASM was conducted with excellent results and no action items were assigned. As requested, all subsequent actions were delegated to the LaRC Procurement Office.

\section{Lessons Learned}

Program should prepare well for ASMs, spending significant time rehearsing in realistic settings and answering questions from review teams. Programs should be prepared for the unexpected in major procurements by including Risk Based Acquisition Management (RBAM) in the Risk Management Plan.

\section{Provide Early, Comprehensive Test Facility Needs Definition (P5)}

\section{Driving Events}

In an effort to reduce duplicity and cost, NASA has evolved and consolidated its test facilities over the past 10 years. This reduction in duplicity makes it unlikely that similar facilities will be available for "fly-offs" required under a competitive environment. Additionally, test facility investment and sustainment is required to ensure that the facilities remain in a state of readiness to support program/project objectives. Relevant work in such facilities ensures retention of staff expertise for safety and for effective real-time management of the testing process. As an example, an independent assessment performed by the ARES Corporation determined that the test facilities available for RS-84 component and prototype testing were insufficient. In addition, during 2003, NGLT unsuccessfully attempted to execute multiple test programs at the Stennis Space Center's (SSC's) E1 Test Facility. These included the Integrated Powerhead Demonstrator's (IPDs) Oxidizer Turbopump (OTP), Fuel Turbopump (FTP), RS-84's Battleship Preburner (BSPB), and TR-107's Preburner (PB)/Thrust Chamber Assembly (TCA). Ultimately, the TR-107's PB/TCA testing was removed from the contract due to limitations in facility capability and capacity.

\section{Lessons Learned}

Limit test projects if required facility systems are not available. Avoid overly optimistic phasing of test facility projects and rely more heavily on historical capabilities. Allocate funding, as necessary, to allow for construction or modification of back-up facilities for mission-/schedule-critical tests. During proposal evaluation, incorporate a process/procedure for evaluating the test requirements against known capabilities and capacities. Verify that existing and future test projects are considered along with built-in contingencies to reduce the schedule risks associated with overlapping tests.

\section{Assess Project Vendor Base Early (P6)}

\section{Driving Events}

A contractor proposed to deliver a sub-scale preburner for the RS-84 Project to SSC within 6 months. The premise was its similarity to previously constructed hardware. However, as the design evolved, the similarities began to diminish, due primarily to differences in life and operating pressure requirements. A failure during the single-element testing also showed the need to make significant modifications to the original element design. Testing eventually began 9 months late, causing numerous schedule conflicts with other programs at SSC, as well as cost increases, which resulted in scope reductions. Delays in sub-scale main injector testing were estimated to be 12 months or more at project cancellation. Additionally, the ability of vendors to meet manufacturing schedules based on proposal estimates was greatly exaggerated. Schedule delays were caused by low production rates and by defects, which required rework of various parts.

\section{Lessons Learned}

Programs should perform a thorough assessment of a manufacturing vendor's capability to produce spacequalified hardware and invest strategically to maintain necessary skills and capability for both near-term and far-term milestones. The government should critique proposals based on current requirements, not on past concepts with similar requirements. Programs should choose vendors based on current ability to perform, not solely on prior performance. 


\section{Schedule}

This section covers creating a nominal timetable for use of resources and achievement of result, tracking, and updating (i.e., planned versus actual), and the systems and teams involved in accomplishing those activities.

\section{Develop Detailed Schedules as Early as Possible (S1)}

\section{Driving Events}

NGLT Systems Analysis $1^{\text {st }}$ Launch Vehicle Design Cycle.

\section{Lessons Learned}

Perform adequate planning and develop realistic schedules with adequate margins in coordination with the analysts and functional leads. Allow internal events to drive the schedule within the preplanned margins. Perform adequate assessment of the impact of external events and re-baseline the schedule if warranted.

\section{Develop an Integrated Master Schedule in the Formulation Phase (S2)}

\section{Driving Events}

Due to the creation of NGLT as a merger of two different programs, the Program had not fully achieved one integrated master schedule linking all NGLT projects with standardized schedule formats at the time of Program closing. There was some difficulty identifying all key interrelationships between the projects. Another hindrance was the discrepancies with the Integrated Budget and Performance Document (IBPD) milestone dates and the milestone descriptions, especially during the merger process. Later, NGLT placed the milestones under full configuration management.

\section{Lessons Learned}

Programs should clearly identify milestones that all projects need to meet (versus a roll-up of projectlevel milestones) during formulation. This would allow the projects to produce schedules with direct links to a program integrated master schedule. The programs should require early compliance with schedule standardization guidelines, with some accommodations for contractor issues.

\section{Ensure Adequate Schedule/Staffing for Procurement Phase (S3)}

\section{Driving Events}

During the $X-43 C$ procurement phase, the project failed to fully appreciate the timeline to execute respective procurement actions resulting in extended schedule. The full timeline duration from source evaluation board review to award was approximately one year.

\section{Lessons Learned}

The project should work with procurement staff to ensure that all issues have been addressed in developing a realistic procurement schedule, and then staff the procurement appropriately to ensure that the schedule can be met (right skill mix/number).

\section{Ensure Adequate Margin in Test Scheduling (S4)}

\section{Driving Events}

ARES Corporation conducted an independent assessment at NASA's request. At the time of the independent assessment, it was determined that the RS-84 prototype phase duration and funding were likely to require either a schedule extension or the immediate start of fabrication of intermediate generations of major new components in order to complete component development testing, engine system testing, and possible hardware modifications due to design changes. Contingency cost and schedule to address several potential technical issues such as combustion instability, coking, ignition, durability, and material compatibility were not defined.

\section{Lessons Learned}

Formulation-phase schedules should include a realistic developmental test phase with margin that takes into account hardware repairs, facility maintenance, shift operations, re-engineering, and other real-world issues.

\section{Budget (B)}

Budget is, as noted above, part of the plan. It covers the location, tracking, and fiscal processing of resources. This categorization breaks "budget" out as a distinct element simply because it received so much attention. 


\section{Credible, Independent Cost Estimates are Needed Early in a Project (B1)}

\section{Driving Events}

The X-43C Project was a complex hypersonic flight demonstration. Three flight elements were linked to perform the mission. This scenario was similar to the Hyper-X (X-43A) Program. with the exception of the DV propulsion system. The $X-43 C$ Project developed an internal cost effort using X-43A actual cost data and heritage United States Air Force (USAF) engine cost data. Two independent cost estimates were performed that were within $10 \%$ of the project estimate. Contract proposal estimates came in more than $50 \%$ over these estimates. This created significant problems for NASA and the USAF, ultimately contributing to its cancellation.

\section{Lessons Learned}

The Agency should possess the ability to perform credible, independent cost estimates. This expertise could be externally procured from DoD or industry contractors. Major procurements should not be awarded before such a cost assessment is accomplished. NASA should implement multi-phase procurements, with options for major development in later phases and/or competitive awards of a separate conceptual design/cost development contract prior to competition for major hardware development contracts.

\section{Clearly Establish Reserves, Schedule Margin, and Spending Profile Early (B2)}

\section{Driving Events}

The X-43C Project budget and milestones were established well ahead of detailed cost and schedule analysis. Per Office of Aerospace Technology (OAT) policy at that time, no budget reserves or schedule margins were allowed. As project cost and schedule requirements grew, the only choice was to slip the first flight. The original spending profile was also not compatible with efficient procurement of flight hardware. Inability to adjust the spending profile forced the project to rearrange cost elements to match the profile, adding risk and extending the schedule. Lack of effective reserves, complicated by OAT 1-year spending metrics, exacerbated the problem.

\section{Lessons Learned}

Programs should establish preliminary project budgets with adequate reserves and schedule margin adjusting budget and spending profiles as better information is developed. Programs should allow rollover of unspent first-year reserve funds into the next year. The program should track and reclaim unspent reserves if they accumulate to excess.

\section{Centralized, Standardized Resources Integration is Critical to Success (B3)}

\section{Driving Events}

Budget errors, omissions, and inconsistencies during formulation, coupled with the need for a focal point to respond to and coordinate with Headquarters Management and Center Chief Financial Office (CFO) personnel, were driving events. Complicating factors were introduced into the current resource environment as a result of the implementation of fullcost accounting and the IFM System. There was also a constant stream of questions and requests for budget information.

\section{Lessons Learned}

Programs should establish a central resources integration office and baseline the budget as quickly as possible, using a formal mechanism for tracking and approving changes (e.g., NGLT Program Requirements Control Board (PRCB). Detailed example: annotate budget spreadsheets with full configuration-control information, including a revision $\log$ ).

\section{Diligence is Required to Prevent Unauthorized Expenditures Under the Current Integrated Financial Management System (B4)}

\section{Driving Events}

Currently, it is possible to charge to a project code without a project manager's or business manager's approval. This has happened at least once on a particular project; it was not detected until it was too late to recover the funds. In cases like this, it is difficult to effectively manage the project budget and assess cost performance against the plan; at best, cost data are 4 weeks old.

\section{Lessons Learned}

Currently, IFM is not mature enough to effectively manage in-house project expenditures (e.g., no Earned Value Management (EVM) capability). Managers need a backup system until IFM evolves this capability. 


\section{Project Plans Should Accommodate "Real World" Funding Disbursements (B5)}

\section{Driving Events}

Procurements and schedules have been significantly impacted by Continuing Resolutions (CRs) and other budget cycle issues. In addition, Centers often take a large percentage of (incremental) CR fund allotments for operating accounts, leaving a much smaller percentage for the project's tasks, causing schedule slips due to the inability to fund contracts onschedule. Problems are exacerbated by the uncertainties and risks associated with advanced technology development.

\section{Lessons Learned}

Project managers should develop a strategy for planning and scheduling that accounts for worst-case budget disbursement scenarios. Projects should also keep Headquarters offices informed of impacts such as Center use of CR allotments.

\section{E. Agreements (A)}

This very broad concept addresses the understandings reached so that resources can be allocated-or other actions taken-based on expectations of results and criteria for achieving those results. These agreements include contracts, grants, cooperative plans, articulation of a partnership, etc.

\section{Teaming Between Government Agencies for Early Technology Development Can Provide Significant Leverage (A1)}

\section{Driving Events}

The development of the VSR\&T Hypersonic Technology Experiment (HyTEx) Re-entry Testbed demonstrated that a properly constructed government partnership, which utilizes the most appropriate technical competencies and unique national assets, can provide a very efficient and unbiased approach for the demonstration and assessment of component technology performance. This model also minimizes duplication of effort and provides opportunities for leveraging, collaboration, and cost sharing where synergistic technology needs exist between various government organizations. With shrinking research and development funding available for technology development and maturation, significant benefits can be realized through pooling inter-Agency resources to increase leveraging opportunities between government organizations. The flexibility afforded by the use of existing government assets can allow for timely demonstrations of component technologies, allowing those technologies to be incorporated at a more mature level (reduced risk) earlier in the system development process.

\section{Lessons Learned}

A government teaming approach provides a viable option for the demonstration and assessment of component-technology performance. Specifically, in the case of a government-team approach, utilize each organization's unique expertise, capabilities, and infrastructure (national assets); streamline the acquisition process by taking advantage of agreements in place between NASA and other government organizations and between various NASA Centers; allow a government-led team to act as a broker to coordinate component-technology demonstrations between appropriate test platform providers and the technology developers.

\section{Leverage Technology Expertise and Hardware from Other Government Programs (A2)}

\section{Driving Events}

The Turbine Based Combined Cycle (TBCC)/Revolutionary Turbine Accelerator (RTA) project needed a high-performance turbine engine core. A new Centerline turbine engine development would cost at least \$1B. The project was able to utilize existing assets from the DoD to provide the core of the turbine engine (i.e., YF-120 engine). The Project included DoD personnel on Integrated Technology Development (ITD) teams to leverage their expertise in turbine engine development, extensive experience with testing aggressive engine systems, and knowledge base of the YF-120 engine. It also included government technical experts from NASA and DoD in ITD teams to leverage their knowledge/involvement in base technology programs/projects such as Ultra-Efficient Engine Technology (UEET), Propulsion Research and Technology (PR\&T), Integrated High-Performance Turbine Engine Technology (IHPTET) and Versatile, Affordable, Advanced Turbine Engine (VAATE).

\section{Lessons Learned}

Programs should canvas the government and leverage as much technology expertise, hardware, and facilities as possible from other programs to maximize return on NASA investments. 


\section{Partners Need Open, Honest Communications (A3)}

\section{Driving Events}

The X-43C Project was a partnership between the United States Air Force Research Laboratory (USAFRL) and three NASA Centers. The Project's management team aimed to utilize the strengths of each partner and minimize duplication of efforts to conserve resources. One NASA Center repeatedly tried to dramatically increase their management role in the program. Even though this Center appeared to accept their assigned role, they continually appealed to every level of authority in an attempt to have the Project structure altered. Eventually, an independent review of the project's organization by the Independent Program Assessment Office (IPAO) validated the basic formulation of the project and its assignment of roles.

\section{Lessons Learned}

Select partners based on demonstrated strengths, matched with project needs. Construct partnership agreements with in-depth descriptions of how the partners will actually execute. (See lesson learned A2.) Hold face-to-face negotiations with all partners in attendance, so everyone benefits from the total of communications. Ensure that all participating partners understand and fully subscribe to their roles from the outset.

\section{Complex Projects Require Detailed and Specific Agreements Between Agencies (A4)}

\section{Driving Events}

$\mathrm{X}-43 \mathrm{C}$ began as a Joint NASA-USAF flight project involving three NASA Centers and the Air Force Research Laboratory (AFRL). The Project Manager inherited a relatively simple, brief Memorandum of Understanding (MOU) with the USAF that was based on a preliminary understanding of complexity and costs. USAF responsibility was for the development and procurement costs of the propulsion system. As contract costs for the propulsion system increased, the USAF was unwilling to increase funding above the level in the MOU. This forced the project to look for ways to reduce complexity and costs in a crisis management mode. OAT policies and differences in NASA and USAF culture made it impossible to indicate reserves in the MOU. This placed a severe strain on partnership relations when inevitable cost growth occurred and ultimately contributed to the Project's cancellation.

\section{Lessons Learned}

Develop detailed Partnership Agreements that are based on sufficiently mature project formulation, or specify a definite schedule for revisions to incorporate details as understanding is achieved. Agreements should have the detail to ensure a true understanding of each party's responsibilities. Specifically address responsibility for cost growth and indicate both budget and schedule reserves in the agreement. Sign agreements at levels high enough to ensure budget commitments can be met.

\section{Ensure Safety Requirements are Agreed to by Government Partners (A5)}

\section{Driving Events}

On the IPD Project, a significant contract modification was made on a DoD-managed contract with MSFC serving as the technical lead. MSFC had no input on the modification and, as a result, hardware that failed to meet minimum NASA S\&MA and accepted industry standards was accepted into the test article. Specifically, the hardware was "prooftested" at only $80 \%$ maximum power level (with standard practice for pressure vessels being 125 $150 \%$ ) and no post-proof non-destructive evaluation was performed. As a partner with DoD on the subject project, MSFC reluctantly accepted hardware that failed to meet minimum Agency S\&MA requirements.

\section{Lessons Learned}

In partnering agreements, all partners should be able to influence contract requirements and make changes as necessary. All partners should have the ability to impose additional S\&MA requirements when deficiencies are discovered.

\section{International Relations Must Be Continually Nurtured (A6)}

\section{Driving Events}

In the fall of 2002 and 2003, a few members of NGLT's staff visited several countries in Europe to evaluate potential cooperative efforts. Upon these visits, the staff found that the cancellation of the $\mathrm{X}$ 38 in 2002 left very bitter feelings toward NASA by the European aerospace community. During these visits, the staff was able to initiate relationships with several companies and government organizations. Contact has continued at a very low level. 


\section{Lessons Learned}

NASA needs to continuously build international cooperation at the performing level. If NASA maintains a small effort, the Agency can ramp up quickly, as needed.

\section{International Agreements Process Within NASA Needs Streamlining (A7)}

\section{Driving Events}

NGLT determined that it would be advantageous to partner with the Australian Centre for Hypersonics at the University of Queensland to obtain flight data for hypervelocity scramjet flow physics in a cost-sharing arrangement. The process, from initial discussion to approval from NASA Headquarters for a sole-source procurement involving a foreign entity, took approximately 15 months. Difficulties in budget phasing, technical progress, and communication resulted due to the duration of this process. (The effort was ultimately not pursued due to changes in program direction.)

Enterprise-level approval was required for policy compliance. However, due to Center roles and responsibilities, approval of NGLT program management at MSFC, as well as line management at LaRC, was required. Guidance from Center and Headquarters export control officials was inconsistent at times, resulting in delays to interpret policy guidance and ensure approval of appropriate agreements. The DoD identified existing data exchange mechanisms that appeared to cover the scope of data exchange between the U.S. and Australia for this project. However, NASA could not provide clear guidance on the use of these mechanisms or partnerships with DoD agencies that involve international cooperation.

\section{Lessons Learned}

Streamline the process by coordinating all international agreements and procurements (if necessary) through Headquarters functional offices, instead of the corresponding Center offices. Initiation of requirements should be made through program, and enterprise-level management. Engage appropriate Agency personnel to consider policy options (i.e., procurement, export control, legal) and identify areas of concern as early as possible. Maximize the use of existing project arrangements and data-exchange agreements (including those established through the $\mathrm{DoD}$ ) to eliminate the need for NASA to pursue separate agreements if a suitable mechanism already exists.

\section{Industry Must Control Resources When Tasking a Government Laboratory (A8)}

\section{Driving Events}

NASA Centers often desire to provide support (tasks) to industry-led proposals. This is typically accomplished via a Government Task Agreement (GTA). This agreement is essentially a subcontract to a NASA Center to perform work for a company. However, funding for this work does not come from or through the company to NASA. As a result , the company does not have full management control over the NASA task. For example, a TPS technology developer requested a NASA Center to perform a series of tests. In fact, the Government facility did not have the test capability they claimed to have in the GTA and was unable to perform the testing. In another case, the Government facility did not perform the work agreed to in the GTA because other higher priority tasks bumped the work from the facility. Industry does not control the resources and, therefore, cannot redeploy to another test facility, thus endangering project success.

\section{Lessons Learned}

Avoid GTAs where the industry partner does not control the resources. Until other avenues are developed, industry should utilize other mechanisms, such as Space Act Agreements, to engage unique government laboratory capabilities.

\section{Streamline Contractor Data Deliverables (A9)}

\section{Driving Events}

The original 2nd Gen RLV Program contract awards contained excessive contractor data deliverables that NASA did not have the resources to evaluate. The Airframe contract was renegotiated prior to the Option 2 award. At that time, the Contracting Office Technical Representative (COTR) generated a reduced set of data deliverables for the Northrop Grumman TA-2 program in order to lower overhead costs. Monthly reports became quarterly reports, and many documents were eliminated outright. The result was an increased number of engineering hours available to perform technical work within the budget constraints for Option 2.

\section{Lessons Learned}

Streamline data deliverables to prevent large contractor support labor costs; avoid inserting Data Requirements Documents (DRD) "boilerplates" into RFPs. Do not request more financial or technical data than the organization can actually analyze. 
10. Standardize and Assure Earned-Value Clauses in Contracts are at the Lowest-Possible Level (A10)

\section{Driving Events}

Due to different (ASTP, $2^{\text {nd }}$ Gen RLV) contract clauses pertaining to business-related reporting requirements (deliverables), some prime contractors were not required to report EVM data and schedules at a low enough level to facilitate adequate schedule and budget analysis. Business data deliverables were interpreted to be reportable only at the top Cost Performance Report (CPR) level, which is much too high to perform analysis or projections of problems and issues that may need to be addressed.

\section{Lessons Learned}

Assure clauses are incorporated into the contract that require contractors to provide electronic EVM data at the lowest planning level, as consistent with NASA/Program-level guidelines for level of EVM.

\section{Contract Statement of Work Should Address Critical Spares (A11)}

\section{Driving Events}

The failure of a pressure control valve during a test caused two pilot-operated relief valves to lift on the run tank, which was a driving event for the Auxiliary Propulsion Project (APP). A lack of spare hardware and soft goods resulted in several weeks of schedule impact that could have been mitigated. During testing of the Aerojet Reaction Control Engine (RCE), there have been several hardware failures. The lack of ready spares has significantly delayed the completion of testing. The Aerojet RCE is a new non-toxic, dual-thrust technology development with many unknowns. The spares philosophy should encompass manufacturing spares as well as test spares.

\section{Lessons Learned}

The statement of work (SOW) for new contracts should request a risk analysis of the testing/manufacturing planned for the project with critical hardware items identified and a spares plan included. The contract should have sufficient funding to initiate the spares procurement. Manage critical spares as project risk items.
12. Contracts Should Allow Industry to Plan Future Work at an Adequate Level of Depth (A12)

\section{Driving Events}

An NGLT contractor not yet under contract requested a schedule change during one project phase that would impact another project phase. The government was unable to evaluate the change because the contractor was not allowed to produce a detailed schedule for future phases of the project.

\section{Lessons Learned}

Program should allow contractors to plan future work to a level of detail necessary to facilitate assessment of proposed changes.

\section{Tie Technology Contract Option Periods to Work Scope and Limit the Number of Options Per Year (A13)}

\section{Driving Events}

As part of the 2nd Gen RLV Program, contracts were developed for technology development with plus additional option periods. The option periods were not based on the technical milestones but were based on program funding cycles and did not allow the contractor to optimize their SOW across the option periods. Long-lead procurements were a particular issue. As certain parts of the technology development incurred schedule slips, the project ended up with overlapping options so that work did not have to be stopped on other activities. At the end of the option period, the project was often not at a logical stopping point. If the next option period was not awarded NASA would have lost the return on the previous investment. In some cases, NASA negotiated multiple options in the same fiscal year, diverting time and energy from the technology development task.

\section{Lessons Learned}

Programs should tie contract option periods to the technology development work plan, allow for longlead procurements of effort needed for future options, and minimize the number of option periods to one per year. 


\section{Increase Time Between Option Award and Acceptance Test Plan (ATP) (A14)}

\section{Driving Events}

Awarding tasks in options is problematic for industry. A 30-day period between a cancellation decision of an option and a new task inception did not allow sufficient time to re-deploy staff to other programs. Option "gates" created anxiety and uncertainty at the contractor level and disturbed the efficient flow of technical progress.

\section{Lessons Learned}

The Agency should increase the period between option award notification and the authority to proceed from 30 days to 60 days.

\section{F. Execution (E)}

This section includes all lessons about implementation of the plans, the implementers, the associated sites and environments. These are lessons related to technology development and/or demonstration, especially where a specific technology is considered.

\section{Proper Government Insight Planning is Required (E1)}

\section{Driving Events}

Due to various internal and external drivers, recent space transportation programs have performed several cycles of program formulation, initiating and canceling projects prior to completion. Several models and management strategies have been employed related to teaming and contracting with industry. The RS-84 government/industry team developed an excellent insight relationship that should be considered by other projects. Recent experience within NASA has revealed the need to maintain adequate skill and insight levels for complex space initiatives. The CAIB Report cited lack of adequate technical insight for critical safety issues and recent development experiences such as X-33 and X-37 also reveal a lack of government involvement in key assessments such as technology readiness and design margins.

\section{Lessons Learned}

NASA should provide technical experts to review contractor data deliverables and provide independent analysis in critical, high-risk areas. Projects should decide early on the level of insight required and should allocate resources for that work. Government insight teams and their industry counterparts should communicate on a regular basis. The government should not relieve the contractor of responsibility for success. However, contracts must account for the role of government, and the contractor should be rewarded for working with insight teams.

\section{Independent Analysis of Critical Items can Save Money (E2)}

\section{Driving Events}

The IPD Project conducted liquid-oxygen powerpack-test operations that required that detailed test requests be generated, processed, and approved by multiple entities. The test request was generated by the contractor, converted to the test area format, reviewed by the contractor and government personnel, and then released to the test operations personnel to execute. On two separate occasions, this process was followed and the request was released to test operations personnel, only to be found in error. Because of the criticality of the request (i.e., IPD had only a single hardware unit) an independent civil service review of the test request was performed. When the test request was compared to the predicted test profiles provided by the contractor, performance redline errors were discovered that would have resulted in premature cut-off of a good test. Catching these errors saved the project the cost associated with conducting a second test and subsequent test turnarounds (approximately $\$ 100 \mathrm{~K}$ apiece). This check avoided cost overruns and schedule delays; however, errors in other performance values could have resulted in a loss of test articles.

\section{Lessons Learned}

Programs should ensure there is an independent review of mission-critical functions before executing them.

\section{Prime Contractor Should Be Responsible for Inspections (E3)}

\section{Driving Events}

The IPD Project utilized contracts based on Air Force standards with prime contractors. For a research and development system, this allowed the contractors to define inspections and quality control requirements. In a cost-saving measure, the engine integrator contractor chose to delegate to their subcontractors the responsibility for performing final inspections on hardware they fabricated prior to shipment. Much of the delivered hardware configuration was correct; however, there were several pieces that were not 
manufactured to print, which impacted the engine assembly schedule. Similar problems occurred during duct, turbopump, and preburner fabrication. The root cause of most of these issues was subcontractor methods of operation. If the final inspection process was performed by the prime (or possibly by an independent inspection group), it is likely that these hardware discrepancies would have been detected prior to installation (at which point the greatest schedule impact is experienced). The prime contractors appeared to have higher quality inspection standards and capabilities than many of the subcontractors.

\section{Lessons Learned}

In contracts involving hardware manufacturing or processing, NASA programs should stipulate that primary and final inspection responsibility be maintained at the prime contractor level. The prime should perform as many of the required inspections as possible.

\section{Involve Industry Early in Research and Technology Activities (EA)}

\section{Driving Events}

In the $2^{\text {nd }}$ Gen RLV Program task, "Ceramic Matrix Composite Control Surface Technology Development," the in-house/vendor team elected to use a processing approach that reduced processing risk by fabricating multiple, separate components, subsequently assembling them using fasteners. Much success was realized using this approach: a Carbon/Silicon Carbide (C/SiC) structural element and a half-scale $\mathrm{C} / \mathrm{SiC}$ subcomponent were successfully fabricated and tested under extreme environments never before experienced by any hot structure component. However, through participation in the X-37 hot structure control surface program, the project learned that the separately processed and bolted assembly approach cannot meet tight manufacturing tolerances required for flight control surfaces.

\section{Lessons Learned}

Increasing the involvement of knowledgeable personnel from aerospace prime contractors in technology development programs ensures that products will have greater utility to aerospace applications.

\section{Streamlined Design Review Processes can be more Effective (E5)}

\section{Driving Events}

The VSR\&T Project HyTEx Re-entry Testbed Preliminary Design Review (PDR) process was performed using concurrent engineering techniques to significantly reduce the overall design review cycle time and travel requirements without compromising the comprehensive breadth of the design review process. The HyTEx government partnership took advantage of best design review practices followed by the various NASA Centers, DoD, and the Department of Energy (DoE) to derive a streamlined design review process.

\section{Lessons Learned}

A streamlined design review process can save time and money, while maintaining an appropriate depth in the review process. NASA programs should carry out proper planning prior to the review and utilize fully engaged participants. Some specific recommendations:

1. Define design review objectives, exit criteria, and process criteria to convene the Board early on;

2. Management buy-in on process to be followed is critical early on;

3. Identify reviewers, screening teams, review teams, pre-board members, and board members that are willing to engage in the process;

4. Require electronic server-based tools to capture design review documentation and to support the Review Item Discrepancy (RID) process;

5. Provide review data packages prior to formal presentations with a short pre-review period where pre-RIDs are accepted (with time needed to review before presentation);

6. Design review presentations are limited in duration with a hard cut-off for RID submission at the end of the presentation process; this requires reviewers and screening/review teams to be present and engaged;

7. Screening teams assign RIDs to the appropriate review teams at the end of each day's presentation; 
8. Review teams disposition present RIDs for pre-Board actions following formal review presentations (i.e., do not solve the problem but assign the appropriate action);

9. Pre-Board makes recommendation whether or not to convene the Board based on predetermined criteria; and

10. Management out-briefs of the review process and results should be planned and scheduled up front.

\section{Automated Tools Cannot Replace Experienced Analysts (E6)}

\section{Driving Events}

In the NGLT SAP, the automation of life-cycle tools was attempted, but the automation was not sufficiently flexible to eliminate the need for experienced expert human analysts.

\section{Lessons Learned}

Programs should not rely solely on automated tools. Human experts should remain in the loop.

\section{G. Technology Integration (T)}

This theme addresses SE\&A as applied to provide feedback and adjustments within "program-phase themes" (i.e., "requirements" through "execution") regarding considerations for technology per se. For example, this covers the formulation, measurement and analysis of TPMs as well as modifications-due to TPM-based feedback-to plans and agreements.

\section{Rigorous Systems Engineering is Needed in Technology Projects (T1)}

\section{Driving Events}

It was noted by the TBCC Project that timely detailed systems analyses/engineering was needed within projects to make effective cost/benefit decisions regarding configurations and technologies. For example: early in the TBCC Project, legacy hardware (HiMATE augmentor rig) was proposed for flame stability testing. However, cost benefit analysis, systems analysis, and leak testing of hardware showed that new rigs (flame stability and annular/sector rigs) would be technically beneficial and financially prudent. The RS-84 Project identified a single-shaft turbopump as the baseline at the time the proposal was negotiated. Over time, it was discovered that a single shaft for the turbopumps would require significantly more risk management than previously identified. The systems engineering process allowed this to be incorporated into the program decision-making process. During the Northrop Grumman Reaction Control System (RCS) Liquid Oxygen (LOX)/Ethanol testing, the project experienced three occurrences of a failure of the disilicide coating on the $\mathrm{Cl} 03$ chamber. The project team was under significant pressure due to schedule delays, so an attempt was made to apply a quick fix of the problem without fully understanding the issues. However, the Project Office required the contractor to perform a full fault tree analysis of the problem before attempting any solutions. The team subsequentiy determiñed that a new Platinum-Iridium (Pt-Ir) chamber, rather than the coated C103 chamber, could be used to meet the test objectives without having to solve a coating problem not in the task objectives.

\section{Lessons Learned}

SE\&A should be executed within technology projects to ensure timely decisions (which are supported with an appropriate depth of analysis e.g., cost/benefit) and coordinated with top-down program-level systems engineering and analysis/requirements flowdown. Programs should ensure the systems engineering discipline is applied even when stress is high and time is short.

\section{A Rapid Response Systems Analysis Team is Invaluable (T2)}

\section{Driving Events}

Routinely, questions (many hypothetical) from Program stakeholders arose during Program progression. Answering some of these questions called for analysis of various concepts and architectures that were not previously identified.

\section{Lessons Learned}

Programs should set aside a quick response "reserve" of resources (manpower and budget) to perform midcourse checks and respond to senior management "what if" inquiries as necessary.

\section{Effective Use of the "Value Stream" Method Requires Active Engineering Organization Participation (T3)}

\section{Driving Events}

The Program incorporated "Value Stream" as a method to link goals and objectives to tasks being performed. Because of competing priorities, Value Stream often did not have the right level of 
engineering organization participation adversely affecting the results.

\section{Lessons Learned}

Programs should ensure performing engineering organizations are tasked and funded to support activities as a part of on-going design activities, rather than as "add-ons."

\section{Early Development of a Systems Engineering Management Plan is Critical (T4)}

\section{Driving Events}

NGLT experienced continual disagreement over processes, procedures and products to be used by the Program's SE\&A teams, all of which came from different legacy programs, each possessing different requirements and Center perspectives (e.g., esearch versus development). For example, inconsistencies in weights and sizing models and differences in definitions of subsystems, combined with insufficient technical exchange with the various architectural teams, led to incorrect interpretation of data, and inaccurate and/or misleading results that required rework.

\section{Lessons Learned}

Programs should define, plan, and agree to processes, procedures, and products for the SE\&A process as early as possible and formally document in a SEMP.

\section{Establish and Flow-down Technical Performance Metrics (T5)}

\section{Driving Events}

ARES Corporation completed an independent assessment of the IPD Project at the request of NASA. At the time of the independent assessment, it was determined that IPD Project TPMs (e.g., achieve $250-\mathrm{KLb}$ thrust, to throttle between $50 \%$ and $100 \%$, etc.) were not appropriate for project objectives, i.e. development of a start sequence and validation of key components and tools. Unresolved component issues (such as oxygen-turbopump lift-off seal, fuel preburner-combustion instability and oxygen PB ignition) threatened the success of system tests. At the time of the independent assessment, it was determined that NGLT Level 1 TPMs and goals had not been formally translated to Level 2 system TPMs or Level 3 component TPMs. As a result, the technologists had generated Level 3 TPMs without input from the Systems Integration Project (SIP)/SAP on Level 1 goals.

\section{Lessons Learned}

Programs should develop trackable, requirementsbased TPMs that will help manage the project performance based on stated objectives.

\section{Provide Configuration Control of Models, Methods, and Data Sets (T6)}

\section{Driving Events}

Many NGLT analyses had several iterative runs that were captured only by the analyst performing the analysis. The acceptance of this "tribal knowledge" capture is something that cosis time and money in the future by driving the need to "reinvent" analyses to validate the touted solutions.

\section{Lessons Learned}

Adequate documentation must be coupled with configuration control on analytical tools, models, and data sets actually applied.

\section{Freeze Methods/Tools During the Analysis Cycle (T7)}

\section{Driving Events}

In performing simultaneous tools development and systems analysis, it was discovered that analysis activities must be insulated from on-going tool development activities and that tools configuration, and methodologies must be frozen during each design cycle.

\section{Lessons Learned}

Programs should separate tool development activities from analysis activities and freeze the methodologies and tools prior to initiation of each design cycle.

\section{Space Transportation Life Cycle Analysis Tools Need an Overhaul (T8)}

\section{Driving Events}

It was realized early in the NGLT SAP that the analysis tools and underlying databases for life-cycle analysis needed an urgent upgrade. To address this need, SAP created a team called the Life Cycle Analysis Team (LCAT) to develop methodologies to improve the analysis of reliability, supportability, development cost, recurring cost, safety, availability and other life cycle-related parameters. One example of needed improvement is the area of operations costs. Current tools do not allow for the evaluation of creative new methods of performing operations. All 
current tools are based on Expendable Launch Vehicles (ELVs) and Shuttle; accurate cost cannot be developed for operations designs that vary significantly from these operations approaches. One method would be to develop a discrete event simulation to model the operations costs and allow the program to represent costs for more creative operations approaches more accurately.

\section{Lessons Learned}

Continued investment is needed in life cycle analysis tools, methods, and databases. During the development of systems, it is essential to understand impacts on the life- cycle costs, safety, reliability, etc.

\section{Utility Curve Analysis Method Aids Complex System Trades (T9)}

\section{Driving Events}

To design a new rocket engine for the NGLT Program, numerous trade studies had to be conducted. In each trade study, a choice had to be made between competing designs to select the optimal solution for the engine. Potential design options also had to be evaluated against multiple program objectives, some of which conflicted at times. The prime contractor for RS-84 implemented a utility curve analysis to help drive decisions during difficult, complex design trade studies. The method involves polling or surveying of the applicable customer base to allow numerical determination of utility indifference curves. The customer preferences toward program goals such as low-cost, highreliability, high-thrust to weight ratio, etc., were then weighted appropriately. The utility analysis allowed the determination of a numerical score for each potential design solution. The design option with the highest score best met the customer objectives and was selected for the final engine design.

\section{Lessons Learned}

A utility curve analysis approach to assessing detailed trade studies should be considered in future activities, especially where numerous design solutions exist in an environment with multiple program goals and objectives.

\section{H. Organizational Design and Development (OD)}

This section addresses the formal and informal organizational structures and element-to-element relationships. Roles and responsibilities for individuals and groups are key here. Emphasis is on changing to meet changing needs and situations.

\section{A Simple, Clear Management Chain is Critical (OD1)}

\section{Driving Events}

The $X-43 C$ Project was required to report up two management chains to the Center level, one for "programmatic" issues and one for "implementation" issues. These areas of a project are not separable, as they continually interact. In addition, there was also a direct management chain to the Headquarters-level, NGLT Program Management Team. Often, an action would be levied on the project from two or more sources. with slightly different interpretations, disguising the fact that it was a single action. Management issues surfaced that were addressed through one chain, often offending the other. One chain sometimes challenged the other in overlapping areas, causing confusion for the project.

\section{Lessons Learned}

Projects should report through a single, clear Center management chain. Programs should minimize the number of levels between the Project Manager and the Center Director for significant and/or highly visible projects. A single Center-level manager should be responsible for making final decisions at that Center for a particular set of projects.

\section{Project Plans Must Clearly Specify Roles and Responsibilities (OD2)}

\section{Driving Events}

Organizationally, the Booster and launch Services (B\&LS) Project Manager was at the same level as the X-43C DV Contract Manager. The Level III Project Office possessed all technical and managerial expertise required to execute the project scope. The DV Contract Manager did not have budget and schedule authority. DV technical insight was provided by the Level II technical staff. Difficulties arose as the Level II staff attempted to exert the same influence on the B\&LS Project as it had on the DV Contract. A Level II Project Plan that fully explained the project roles and responsibilities and clarified project controls was not approved prior to project cancellation. In contrast, the NGLT SAP management established and documented clear goals and individual responsibilities at the beginning of the project formulation, so that all team members understood what was expected of them.

\section{Lessons Learned}

Programs and Pprojects should write a Project or Program Plan early, leaving some place-holder 
sections in order to establish the control mechanisms that will be employed on the project. Early releases of the plan can be baselined at the project- or program-level only. Specify how critical financial, schedule, and technical decisions will be made. Controls (i.e., approval gates and processes) should be clearly defined in concert with the level of responsibility delegated to the project or sub-project.

\section{Delegate Responsibility and Then Follow Through (OD3)}

\section{Driving Events}

The ASTP (and later NGLT) Program delegated much responsibility for the X-43C Project to LaRC. A single Project Manager was given authority to manage the project for the parent programs. The Program Manager provided general guidance without interfering with project management. Appropriate status reporting was required of all projects by the Program. This arrangement applied a sound management approach and demonstrated trust in the Project Manager and his Center managers. In effect, the Program Manager defined and enforced a chain of command that fully supported the Project Manager's authority.

\section{Lessons Learned}

1. Program Managers should delegate responsibility for project execution, with matching authority, to the subordinate Project Managers. Enforcement of this chain of command facilitates effective project management at supporting Centers.

2. All projects should have a single manager with appropriate authority to execute the project.

3. Status reporting to the Program should be enforced at the lowest level of detail and frequency, consistent with project complexity and visibility.

\section{Identify a Single Leader and Properly Stafi Systems Engineering Activities (OD4)}

\section{Driving Events}

The NGLT Systems Engineering Office was not fully capable of meeting expectations due to inadequate staffing, unclear roles/responsibilities, and inadequate planning. Multiple organizations performed systems engineering functions across multiple Centers with unclear lines of authority.

\section{Lessons Learned}

Programs should have a single authority for systems engineering and integration, obtaining clear commitments from participating Centers on both lines of authority and the deliverable work package. Related staffing issues should also be resolved up front.

\section{Encourage Management and Organizational Development (OD5)}

\section{Driving Events}

NGLT contracted with professional organizational consultants to facilitate the development of management skills within the organization. Workshops focused on developing understanding of individual roles as well as roles of those above, below, and beside them. This basic understanding led to increased effectiveness at all levels of the organization.

\section{Lessons Learned}

NASA programs should provide regular organizational development opportunities to all Program personnel.

\section{Establish Formal Change Control at All Levels (OD6)}

\section{Driving Events}

A formal change control process was not in place at the X-43 Project level (Level II). The Level III project incorporated DV design requirements such as outer mold line, mass properties, and separation point requirements into its Launch System Requirements Document (LSRD). Over the life of the project, changes were made in the DV baseline by the Level II office without official notification to the B\&LS Project (Level III).

\section{Lessons Learned}

NASA programs should establish a formal change control process and critical baselines early at all levels of an activity (Levels I, II, III), and ensure that these baselines are communicated clearly across all elements. 


\section{NASA's Unique Organizational Perspective Can Help in Problem Identification and Resolution (OD7)}

\section{Driving Events}

The IPD Project was the first project to test a liquid oxygen turbopump fully supported by hydrostatic bearings. This unique bearing design benefits include "floating" the rotating shaft on a thin film of liquid oxygen fluid. Because NASA technical experts were not part of the design team (being designed when IPD was an Air Force-only project), a detailed technical review was held prior to the initial test. During this review, concern over electrostatic discharge was raised. The contractor responded that the phenomena had not been encountered in liquid oxygen before and therefore was not a concern. NASA reviewers were aware of similar issues with other contractors and from in-house experience. NASA personnel disassembled a similar in-house turbopump looking explicitly for evidence of electrostatic discharge. Evidence showed that the phenomena had occurred in liquid oxygen, and indicated that the severity of the arcing was sufficient to ignite the carbon lift-off seal in the oxygen turbopump should the arc occur at that seal, with potential catastrophic results.

\section{Lessons Learned}

Critical aspects of contractor designs and tests should be reviewed by NASA subject matter experts to increase the likelihood of success.

\section{Program Integration and Communication (PC)}

This section covers the relationships and interactions between program elements-by formal or informal mechanisms - that correlate to achieving the greater good of the program objectives/goals. Transmittal of information-communication-is an essential precursor to any decision or action. Hence, communication is an integral part of successful program integration in its broadest sense.

\section{Middle-Management Integration is a Powerful Tool (PC1)}

\section{Driving Events}

The NGLT middle-managers forum for integration across the program greatly improved overall program execution. This forum was championed by one middle-manager who knew that his peers would have a tendency to pull away from each other and work in their own "silo." This would have caused a lack of integration across the program and likely less teamwork among the program office staff. The forum set-up caused these middle-managers to take integration seriously and avoided costly breakdowns in communication at their level.

\section{Lessons Learned}

NASA programs should create a middle-managers' forum for integration at the Program Office-level. Program managers should pay close attention to how middle managers integrate with their peers and ensure communication is flowing, thus contributing to improving safety, eliminating duplication, and promoting good working relationships across the elements of the Program/Centers. Programs should also explore the potential for applying this concept at other levels of the organization.

\section{Create an Environment That Will Accept "Bad News" by Management (PC2)}

\section{Driving Events}

A program's accomplishments depend on good, open, and integrated communication. The CAIB Report highlighted the issue of keeping a "code of silence" and its detriment to the success of a program. This occurred within NGLT as well. One example was how the SE\&A function's project-level management had issues in working with each other and the Program Office; as hard as they tried, they could not be as open as they needed to be to resolve their issues.

\section{Lessons Learned}

Programs should consider the "Crucial Conversations" approach used in NGLT, which effectively deals with organizational cultures that historically encourage silence or retribution. Educate/train people at all levels of the organization and give them a set of tools that will help in overcoming this detrimental way of operating.

\section{Document Decisions and Supporting Rationale (PC3)}

\section{Driving Events}

In some instances, there were not enough details regarding the decision rationale for technology and/or launch vehicle analysis for validation of analytical results to prevent duplication of effort. 


\section{Lessons Learned}

NASA programs should provide adequate documentation of decision rationale for validation of analytical results to prevent later duplication of effort.

\section{Standardize and Minimize the Number of Different Project Reporting Mechanisms (PC4)}

\section{Driving Events}

The X-43C Project reported progress to ASTP (later NGLT) first on a monthly basis and later in a Quarterly Report, each with a unique required chart format. During the same timeframe, X-43C reported to the LaRC Center Program Management Council, which required yet another chart format. All chart sets contained largely the same project management data and status reporting. However, the formats were different, requiring the project team to create multiple versions of the same data. This increased the workload and added risk of error due to the rework process.

\section{Lessons Learned}

Programs should adopt a common format for project management reporting and coordinate with Headquarters and each Center's Systems Management Office to enhance communication and reduce workload on project staff. Programs could also develop a "super-set" of formats to cover anticipated reporting needs at all levels.

\section{Project Teams and Systems Analysts Need to Work Closely When Performing Technology Assessments (PC5)}

\section{Driving Events}

Due to the nature in which NGLT was created, there was not initially a tight integration between SE\&A and the technology projects. Technology projects were not cognizant of what was going on within SE\&A activities. In early FYO4, the SE\&A team held a "road show" that took the results of the previous cycle of analysis to all Centers to demonstrate their activities to the technology projects. This team also conducted an Architecture Design and Technology Integration Workshop prior to the start of the next analysis cycle to discuss the technology impacts on system designs and identify a viable baseline and alternate technology options. This workshop provided a forum for technologists to discuss how their technologies impacted system designs with the systems analysts. In the past, Value Stream workshops were held at the end of each cycle to facilitate a meeting between technologists and systems analysts to identify shortfalls in capability versus need.

\section{Lessons Learned}

Technology projects should be made aware of systems analyses that are being performed and the parameters that are being used throughout the assessment process. The use of structured forums at the beginning of the analysis cycle and a Value Stream workshop at the end of each cycle should be a part of any technology program. Representatives from each technology project should be represented on the systems analysis team(s).

\section{Set Clear Expectations in Design Reviews (PC6)}

\section{Driving Events}

At a recent PDR, it became obvious to the Government team that the contractor did not understand NASA's expectations and requirements for the review.

\section{Lessons Learned}

NASA should ensure that expectations and requirements for contract items such as milestones and deliverables are clearly stated in the contract SOW and understood by the contractor.

\section{Effective Vertical Communications are a Necessity (PC7)}

\section{Driving Events}

During the life of the RS-84 Project, several team members expressed frustration with their lack of knowledge regarding activities at the project, program, and Headquarters levels. Team members felt that there was inadequate "top-down" communication.

\section{Lessons Learned}

NASA programs should consider interactive communications rather than the one-way variety such as e-mail. Senior program personnel should schedule times to conduct project team "all-hands" to speak to team members and answer questions. 


\section{Capture "Lessons Learned" Throughout the Project Lifecycle (PC8)}

\section{Driving Events}

During X-43C Project development, many lessons learned from the X-43A Project were incorporated informally by shared technical and management personnel. Because of shared resources, many management and technical decisions and subsequent activities were not formally captured. This situation drove the need to repeat communications regarding decision rationale to new personnel and outside reviewers.

\section{Lessons Learned}

Lessons learned activities should be performed at the working level on a continuous basis throughout the life of a project, as are risk management reviews. Lessons learned activities should be tied to risk management activities because they often result from unidentified, unmanaged, or misunderstood risks.

\section{J. Safety and Risk (SR)}

Safety and risk are affected, often to a first order, by changes anywhere within the Program. Lessons learned in this section are limited in number, since safety is best appreciated as being "everywhere." Additionally, managers of advanced-technologydevelopment projects are increasingly using risk management as a primary tool to guide most aspects of their projects.

\section{Identify and Track Risks Early and Incorporate into Acquisition Strategy (SR1)}

\section{Driving Events}

The X-43C Project compiled and managed risk early in the project formulation. By initiating the risk process early on, project plans and associated reasoning could be explained early and effectively.

\section{Lessons Learned}

NASA programs should prepare risk management plans early in project formulation and include budget analysis and Risk-based Acqusition management (RBAM) activities to serve the project during formulation and startup.

\section{Use a Consistent Risk Management System Across the Program (SR2)}

\section{Driving Events}

NGLT technology content represented risk mitigation activities for RLV. Risk assessment and management were the responsibility of each project team, each of which brought a different system from their legacy programs. The most commonly used system was resident in the Space Transportation Information Network (STIN), but some projects used other Commercial Off-the-Shelf (COTS) tools. While risk management was performed, it was not performed at a uniform level across the Program. The STIN risk tools were under constant development, which also complicated matters.

\section{Lessons Learned}

Programs should select a proven risk management system that represents an industry standard and then train the users in its application, making sure that expectations are understood from top to bottom in the organizations that are to be using the system. Programs should also provide mandatory risk management training to all members of a program/project team (including contractors) with periodic refresher training to accommodate personnel changes.

\section{Develop Specific Pass/Fail Criteria for Risk Reduction Activities (SR3)}

\section{Driving Events}

The RS-84 Risk Management Program evolved as the Rocket Engine Prototype (REP) Project matured. Each IPT conducted monthly meetings, with NASA participation, during which a status of each risk was discussed. Descriptions of risk mitigation/reduction steps were updated and refined, and actions were assigned for implementation of the plans. New candidate risks were presented for review/validation and, if approved, new risks were assigned owners for assessment and planning.

\section{Lessons Learned}

Programs should ensure pass/fail criteria are established as an integral part of the planning phase for risk reduction and mitigation activities. Programs should develop specific decision criteria for implementation of back-up/contingency plans or modification of the design or development effort. 


\section{Perform Technology Risk Assessment as an Integral Part of Systems Analysis Efforts (SR4)}

\section{Driving Events}

A technology risk assessment was performed for NGLT on an uncertain schedule, often hurriedly at the end of an analysis cycle. In some cases, there was inadequate time to fully validate the results of the assessments.

\section{Lessons Learned}

Programs should plan for continual interaction between the end-users and the design anaiysts, such that performance of the risk assessment process will provide the desired benefit.

5. Develop Alternate Strategies when Incorporating New Materials and Processes (SR5)

\section{Driving Events}

ARES Corporation completed an independent assessment of the IPD Project at the request of NASA. The following lessons learned were part of the resulting findings.

\section{Lessons Learned}

Projects should develop and demonstrate qualification processes for flight hardware fabrication and inspection during the prototype design and fabrication phase and develop proven, fall-back approaches (e.g., heavy welded ducts, oxidation resistant coatings, etc.) to control expenditures if fabrication or testing difficulties arise on prototype components. 